University of South Carolina

Scholar Commons

$12-3-2001$

\title{
Three unique coordination geometries involving 1,2-dimethoxy-4,5-bis(2-pyridylethynyl)benzene
}

Jeffrey E. Fiscus

University of South Carolina - Columbia

Sandra Shotwell

University of South Carolina - Columbia

Ralph C. Layland

Lander University

Mark D. Smith

University of South Carolina - Columbia, smith.mark@mail.chem.sc.edu

Hans Conrad zur Loye

University of South Carolina - Columbia, zurloye@sc.edu

See next page for additional authors

Follow this and additional works at: https://scholarcommons.sc.edu/chem_facpub

Part of the Chemistry Commons

Publication Info

Chemical Communications, 2001, pages 2674-2675.

(C) 2001 The Royal Society of Chemistry

http://pubs.rsc.org/

DOI: $10.1039 / B 109849 G$

This Article is brought to you by the Chemistry and Biochemistry, Department of at Scholar Commons. It has been accepted for inclusion in Faculty Publications by an authorized administrator of Scholar Commons. For more information, please contact digres@mailbox.sc.edu. 
Author(s)

Jeffrey E. Fiscus, Sandra Shotwell, Ralph C. Layland, Mark D. Smith, Hans Conrad zur Loye, and Uwe H. F. Bunz 


\section{Three unique coordination geometries involving 1,2-dimethoxy-4,5-bis(2-pyridylethynyl)benzene}

Jeffrey E. Fiscus, ${ }^{a}$ Sandra Shotwell, ${ }^{a}$ Ralph C. Layland, ${ }^{b}$ Mark D. Smith, ${ }^{a}$ Hans-Conrad zur Loye $^{* a}$ and Uwe H. F. Bunz $* a$

a Department of Chemistry and Biochemistry, The University of South Carolina, Columbia, South Carolina 29208, USA. E-mail: zurloye@sc.edu; bunz@mail.chem.sc.edu

${ }^{b}$ Division of Biological and Physical Sciences, Lander University, Greenwood, South Carolina, USA

Received (in Columbia, MO, USA) 14th September 2001, Accepted 30th October 2001

First published as an Advance Article on the web 3rd December 2001

Reaction of the new ligand 1,2-dimethoxy-4,5-bis(2-pyridylethynyl)benzene with different metal centers under similar reaction conditions led to three distinct structure formation processes: molecular ring closure, dimerization, and polymer formation.

In synthetic, covalent organic chemistry the notion of conformers, oligomers and polymers are distinctly separated and irreconcilable. In supramolecular synthesis on the other hand this conception is less stringent. The utilized building blocks and the variety of binding forces that hold supramolecular assemblies together by arranging organic modules in the solid state makes the border of the very notions of conformers, cycles, and polymers more permeable. Here we wish to demonstrate that one organic module 1,2-dimethoxy-4,5-bis(2-pyridylethynyl)benzene $\mathbf{1}^{1}$ can form a supramolecular cycle, a dimer and polymer utilizing different inorganic connectors $\mathrm{Cu}(\mathrm{OAc})_{2}$, $\mathrm{CoCl}_{2}$ and $\left[\mathrm{Rh}(\mathrm{OAc})_{2}\right]_{2}$.

Single crystals suitable for X-ray diffraction $\dagger$ of $\mathrm{Cu}(\mathbf{1})$ $(\mathrm{OAc})_{2} \cdot \mathrm{CH}_{3} \mathrm{OH} 2$ were obtained by layering a methanol solution $(1 \mathrm{~mL})$ of $\mathrm{Cu}(\mathrm{OAc})_{2} \cdot \mathrm{H}_{2} \mathrm{O}(2.0 \mathrm{mg}, 0.01 \mathrm{mmol})$ over a dichloromethane solution ( $1 \mathrm{~mL})$ of $1(6.7 \mathrm{mg}, 0.02 \mathrm{mmol})$, with a layer of pure methanol separating them (20\% yield). Crystals of $\left[\mathrm{Co}(\mathbf{1}) \mathrm{Cl}_{2}\right]_{2} \quad 3$ were prepared similarly, substituting $\mathrm{CoCl}_{2} \cdot 6 \mathrm{H}_{2} \mathrm{O}$ for $\mathrm{Cu}(\mathrm{OAc})_{2} \cdot \mathrm{H}_{2} \mathrm{O}$ and ethanol for methanol $(68 \%$ yield) $\ddagger$ Crystals of catena-poly $\left\{\left[\mathrm{Rh}(\mathrm{OAc})_{2}\right]_{2} \mathbf{1} \cdot \mathrm{CH}_{2} \mathrm{Cl}_{2}\right\} \mathbf{4}$ were prepared similarly to $\mathbf{2}$ except that $\left[\mathrm{Rh}(\mathrm{OAc})_{2}\right]_{2}$ was substituted for $\mathrm{Cu}(\mathrm{OAc})_{2} \cdot \mathrm{H}_{2} \mathrm{O}$ (maintaining the ligand to metal ratio) and ethanol was substituted for methanol (40\% yield). These three systems each form a distinctly different structure and between them, demonstrate the importance of the free rotation of the pyridyl rings around the carbon-carbon bonds for facilitating the formation of the three structure types.

Compound $\mathbf{2}$ demonstrates the preference of $\mathrm{Cu}^{2+}$ for square planar coordination with copper positioned snugly between the two pyridyl rings. The resulting $\mathrm{N}-\mathrm{Cu}-\mathrm{N}(\mathrm{Cu}-\mathrm{N} 2.01 \AA$, N$\mathrm{Cu}-\mathrm{N} 172.98^{\circ}$ ) bonds close an eleven membered, triangular ring (Fig. 1), which is nearly identical to the structures reported by Bosch and Barnes for 1,2-bis(2-pyridylethynyl)benzene. ${ }^{2}$ The square planar coordination of copper is completed by two trans oxygens from separate acetate groups.

Compound 3 contains $\mathrm{Co}^{2+}$, which is found in typical tetrahedral coordination. ${ }^{3}$ This tetrahedral preference, apparently, cannot be conveniently satisfied through a ring closure that would require a rotation of the pyridyl rings away from the $180^{\circ}$ angle found in the copper complex. The result of such a rotation would be an elongated $\mathrm{Co}-\mathrm{N}$ bond. Instead, the pyridyl rings rotate away from each other by $128^{\circ}$ and bind to separate cobalt atoms with bond lengths of $2.03 \AA$, which is typical for $\mathrm{Co}-\mathrm{N}$ bonds. The tetrahedral coordination in each case is completed by two chlorine atoms. The overall structure (Fig. 2) consists of two molecules of $\mathbf{1}$ bridging two cobalt atoms. An inversion center is located in the middle of the dimer.

The polymeric structure of 4 (Fig. 3) results from the linear coordination preference of $\left[\mathrm{Rh}(\mathrm{OAc})_{2}\right]_{2}$. The structure consists

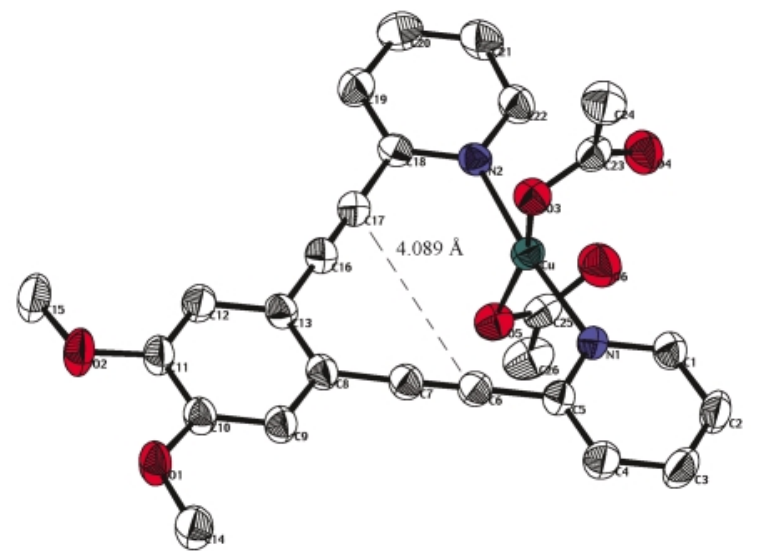

Fig. 1 A single molecule of $\mathbf{2}$. The hydrogen atoms and methanol group have been omitted for clarity.

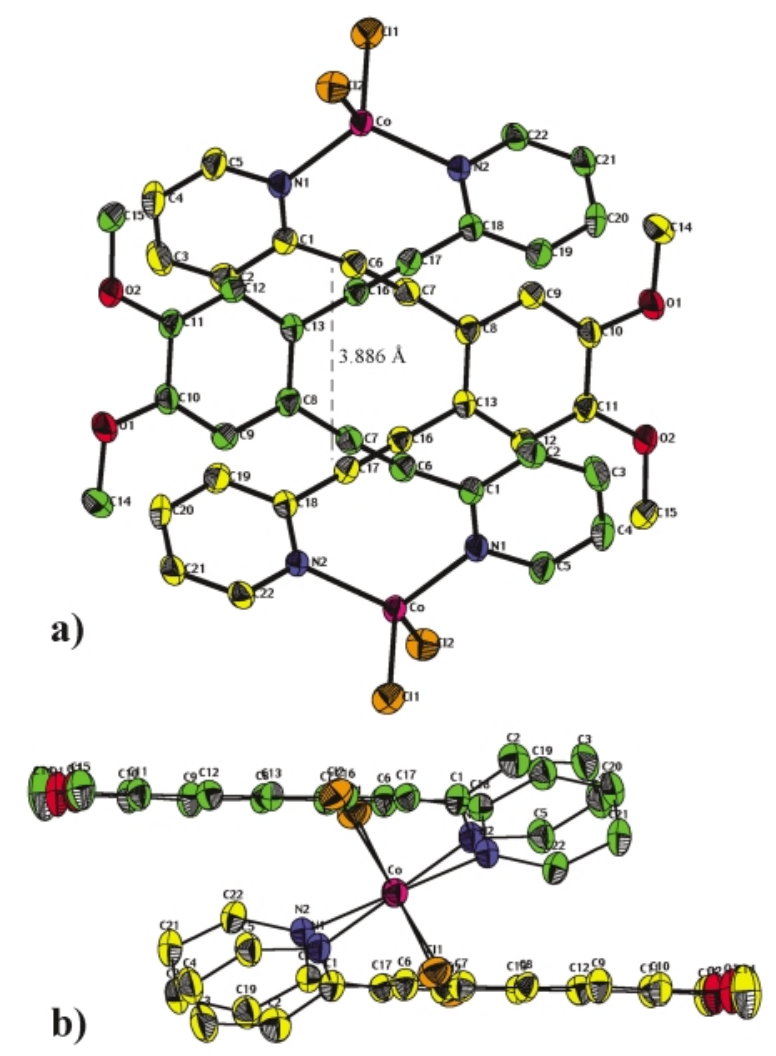

Fig. 2 Hydrogen atoms have been omitted for clarity. (a) a view of $\mathbf{3}$ from above showing the tetrahedral coordination of cobalt; (b) a view of $\mathbf{3}$ from the side showing the opposing orientations of $\mathbf{1}$ and the rotation of the pyridyl rings. 


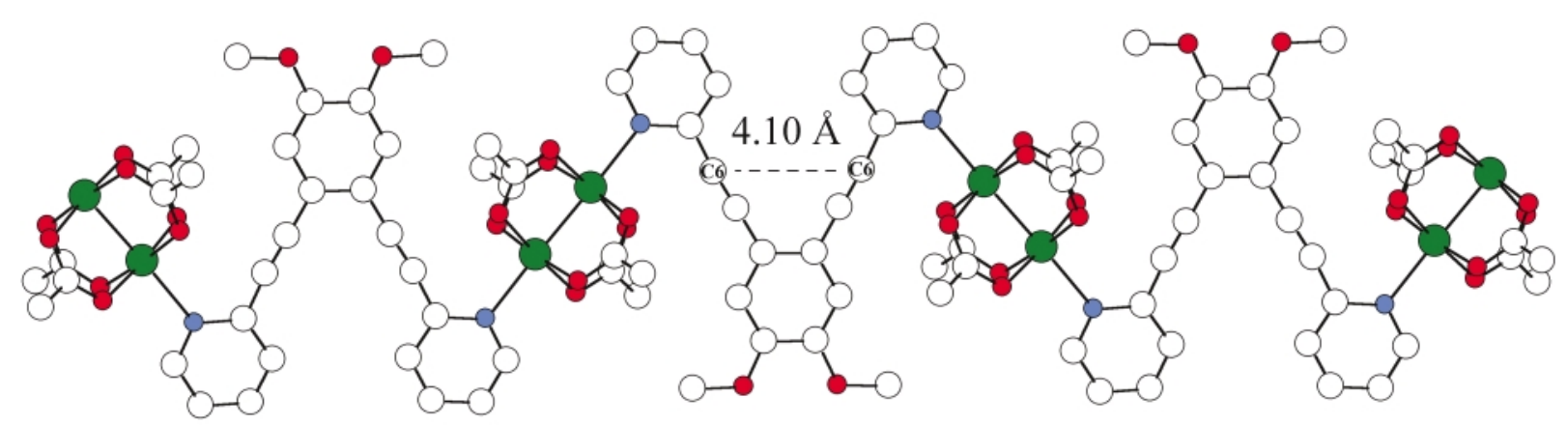

Fig. 3 A view of $\mathbf{4}$ showing the connectivity of $\mathbf{1}$ and the rhodium dimer. Hydrogens have been omitted for clarity.

of two acetate-bridged rhodium atoms that connect to the pyridyl rings of two separate molecules of $\mathbf{1}$ and mimics a conjugated organic polymer. The rhodium is six-coordinate with four equatorial oxygens from the acetate groups, one axial rhodium from the other half of the dimer and one nitrogen belonging to the pyridyl group on the ligand.

Tetrakis(carboxylato)rhodium compounds were first discovered in $1960,{ }^{4}$ but it was not until 1981 that the first polymeric species containing such a rhodium dimer was synthesized..$^{5}$ A survey of the CSD indicates that $\mathbf{1}$ is the largest ligand yet used in such a polymeric species. The polymeric structure is charge balanced, eliminating the need for counter ions competing for binding sites. This leads to higher site symmetry and makes such rhodium dimers attractive building blocks for coordination polymers. ${ }^{6}$ Because of its length, the dirhodium moiety cannot fit between the pyridyl rings and achieve ring closure, as in $\mathbf{2}$, despite the favorable linear arrangement of the binding sites. Consequently, the pyridyl rings rotate outward by $180^{\circ}$ to form a polymer chain with the rhodium dimer bridging adjacent ligands in a zig-zag fashion. This polymer is a supramolecular analogue of the hitherto unknown ortho-PPE ${ }^{7}$ and as such is a fascinating structure. The $\mathrm{Rh}-\mathrm{N}$ distance within the polymer is $2.25 \AA$, typical for $\mathrm{Rh}-\mathrm{N}$ bonds in such systems..$^{5,8-10}$

One interesting aspect of these structures are the carboncarbon separations between the alkyne groups on the ligand $\mathbf{1}$ which, if close enough, could potentially be crosslinked in a Bergman reaction. ${ }^{11}$ In 2 , the closed ring conformation results in a C6 $\cdots \mathrm{C} 17$ separation of $4.089 \AA$. This is almost the same as the C6 $\cdots$ C6 distance of $4.100 \AA$ in 4 , which should represent an unstrained system. By comparison, in 3, the C6 $\cdots \mathrm{C} 17$ distance within the same molecule of $\mathbf{1}$ is $3.886 \AA$, while the alkyl groups on separate ligands are only $3.548 \AA$ apart (within the range for $\pi-\pi$ interactions). This suggests that the copper cation fits between the pyridyl rings without inducing any strain, while in 3, the dimer formation strains the ligand, bending the pyridyl ligands towards one another, which effects a shorter C6 $\cdots \mathrm{C} 17$ distance.

These three structures demonstrate the diversity, which can be achieved using 1 that is made possible by the ability of the ligand to distort itself to the preferred coordination environment of the metal center. While one may expect a slight bending of the pyridylethynyl legs either towards or away from each other, these three structures show that rotation of the pyridyl ring around the ethynyl linkage seems more favorable.

Financial support was provided in part by the National Science Foundation through Grants DMR:9873570 and CHE:9814118 and in part by the South Carolina Commission on Higher Education through Grant CHE:R00-U25. The Bruker CCD Single Crystal Diffractometer was purchased using funds provided by the NSF Instrumentation for Materials Research Program through Grant DMR:9975623.

\section{Notes and references}

$\dagger$ Synthesis of the ligand 1: under nitrogen, 1,2-dimethoxy-4,5-diiodobenzene $(2.00 \mathrm{~g}, 5.28 \mathrm{mmol}),{ }^{12}$ 2-ethynylpyridine $(1.09 \mathrm{~g}, 10.6 \mathrm{mmol}){ }_{13}^{13}$ $\left(\mathrm{Ph}_{3} \mathrm{P}\right)_{2} \mathrm{PdCl}_{2}(50 \mathrm{mg}, 71 \mu \mathrm{mol}), \mathrm{CuI}(50 \mathrm{mg}, 263 \mu \mathrm{mol})$ and piperidine $(15$ $\mathrm{mL})$ are placed in a Schlenk flask and stirred for $24 \mathrm{~h}$ at ambient temperature. Aqueous workup followed by chromatography with EtOAchexanes (1:9) furnishes the ligand in $22 \%$ yield $(395 \mathrm{mg})$ as a colorless powder (mp $\left.154{ }^{\circ} \mathrm{C}\right)$. Spectroscopic data: IR, v/cm-1 $2200(\mathrm{~m}), 1590(\mathrm{w})$, 1570 (s), 1550 (w), 1510 (s), 1460 (m), 1450 (m), 1435 (w), 1425 (w) 1415 (w), $1360(\mathrm{~s}) .{ }^{1} \mathrm{H}$ NMR $\left(\mathrm{CD}_{3} \mathrm{CN}\right), \delta 3.90\left(\mathrm{~s}, 6 \mathrm{H}, \mathrm{OCH}_{3}\right), 7.24(\mathrm{~s}, 2 \mathrm{H}$, aryl$\mathrm{H}), 7.38$ (ddd, 2H, pyridyl-H), 7.77 (dt, 2H, pyridyl-H), 7.82 (td, $2 \mathrm{H}$, pyridyl-H), $8.65\left(\mathrm{~d}, 2 \mathrm{H}\right.$, pyridyl-H). ${ }^{13} \mathrm{C} \mathrm{NMR}\left(\mathrm{CDCl}_{3}\right), \delta 150.28,149.812$, $143.83,136.38,127.54,122.92,118.65,114.67,91.94,88.33,56.34$. MS EI, $m / z, 340\left(100 \%, \mathrm{M}^{+}\right), 341\left(25 \%, \mathrm{M}^{+}\right), 342\left(5 \%, \mathrm{M}^{+}\right), 325\left(\mathrm{M}^{+}-\mathrm{CH}_{3}\right.$, $15 \%$,) $309\left(\mathrm{M}^{+}-\mathrm{OCH}_{3}, 4 \%\right), 263\left(\mathrm{M}^{+}-\right.$pyridine, $\left.97 \%\right)$.

$\ddagger$ Crystal data for $2: \mathrm{C}_{27} \mathrm{H}_{26} \mathrm{CuN}_{2} \mathrm{O}_{7}, M=554.04$, triclinic, space group $P \overline{1}$, $a=8.2357(4), b=12.5088(6), c=13.3128(6) \AA, \alpha=78.3000(10)^{\circ}, \beta=$ $72.1170(10)^{\circ}, \gamma=76.6810(10)^{\circ}, U=1257.12(10) \AA^{3}, T=293(2) \mathrm{K}, Z=$ $2, \lambda=0.71073 \AA$, 11656 reflections measured, 5144 unique $\left(R_{\text {int }}=0.0199\right)$ which were used in all calculations. $R 1=0.0374$ and $w R 2=0.0922$. For 3: $\mathrm{C}_{44} \mathrm{H}_{32} \mathrm{Cl}_{4} \mathrm{Co}_{2} \mathrm{~N}_{4} \mathrm{O}_{4}, M=940.40$, monoclinic, space group $P 2_{1} / n, a=$ 8.5272(6), $b=18.3653(13), c=13.3493(9) \AA, \beta=103.574(2)^{\circ}, U=$ 2032.2(2) $\AA^{3}, T=190$ (2) $\mathrm{K}, Z=2, \lambda=0.71073 \AA, 13541$ reflections measured, 4156 unique $\left(R_{\mathrm{int}}=0.0347\right)$ which were used in all calculations. $R 1=0.0504$ and $w R 2=0.1107$. For 4: $\mathrm{C}_{31} \mathrm{H}_{30} \mathrm{Cl}_{2} \mathrm{~N}_{2} \mathrm{O}_{10} \mathrm{Rh}_{2}, M=867.29$, monoclinic, space group $C 2 / c, a=21.5985(13), b=20.2480(12), c=$ 8.0207(5) ̊, $\beta=103.2650(10)^{\circ}, U=3414.1(4) \AA^{3}, T=190(2) \mathrm{K}, Z=$ $4, \lambda=0.71073 \AA$, 15208 reflections measured, 3504 unique $\left(R_{\text {int }}=0.0545\right)$ which were used in all calculations. $R 1=0.0613$ and $w R 2=0.1222$. CCDC reference numbers 173558-173560. See http://www.rsc.org/suppdata/cc/b1/b109849g/ for crystallographic data in CIF or other electronic format.

1 S. Shotwell and U. H. F. Bunz, manuscript in preparation.

2 E. Bosch and C. L. Barnes, Inorg. Chem., 2001, 40, 3097.

3 N. N. Greenwood and A. Earnshaw, Chemistry of the Elements, Reed Educational and Professional Publishing, Oxford, 2nd edn., p. 1129.

4 I. I. Chernyaev, E. V. Shenderetskaya and A. A. Karyaguba, Russ. J. Inorg. Chem., 1960, 5, 559

5 F. A. Cotton and T. R. Felthouse, Inorg. Chem., 1981, 20, 600.

6 F. A. Cotton, C. Lin and C. A. Murillo, Acc. Chem. Res., 2001, in press.

7 R. H. Grubbs and D. Kratz, Chem. Ber., 1993, 126, 149.

8 T. Niu, J. Lu, G. Crisci and A. J. Jacobson, Polyhedron, 1998, 17 4079

9 H. Kitamura, T. Ozawa, K. Jitsukawa, H. Masuda, Y. Aoyama and H. Einaga, Inorg. Chem., 2000, 39, 3294.

10 F. A. Cotton and T. R. Felthouse, Inorg. Chem., 1981, 20, 584.

11 R. G. Bergman, Acc. Chem. Res., 1973, 6, 25; T. Chandra, J. C. Huffman and J. M. Zaleski, Inorg. Chem. Commun., 2001, 4, 434.

12 J. D. Kinder and W. J. Youngs, Organometallics, 1996, 15, 460.

13 D. E. Ames, D. Bull and C. Takundwa, Synthesis, 1981, 364. 